Citation: Missiuna, C., Pollock, N., Campbell, W., DeCola, C., Hecimovich, C., Sahagian Whalen, S., ...Camden, C. (2016). Using an innovative model of service delivery to identify children who are struggling in school. British Journal of Occupational Therapy. Advance online publication. doi: 10.1177/0308022616679852

Submitted to BJOT: 19 May 2016; Final acceptance: 19 October 2016. Available at http://journals.sagepub.com/doi/full/10.1177/0308022616679852

\title{
Full Title: Using an innovative model of service delivery to identify children who are struggling in school
}

\section{Short Title: Identifying children who are struggling in school}

Cheryl Missiuna ${ }^{1-3}$, Nancy Pollock ${ }^{2,4,5}$, Wenonah Campbell ${ }^{2,6}$, Cindy DeCola ${ }^{7}$, Cathy Hecimovich $^{8,9}$, Sandra Sahagian Whalen ${ }^{5,10}$, Jennifer Siemon ${ }^{11}$, Kaiwen Song ${ }^{12}$, Robin Gaines $^{13,14,15}$, Sheila Bennett ${ }^{15,16}$, Dayle McCauley ${ }^{17}$, Debra Stewart ${ }^{2,5,18,19}$, John Cairney $^{2,20}$, Leah Dix ${ }^{7,8}$ and Chantal Camden ${ }^{15,21,22}$

${ }^{1}$ Professor in the School of Rehabilitation Science, McMaster University, Canada

${ }^{2}$ Scientist with CanChild, McMaster University, Canada

${ }^{3}$ Holder of the John and Margaret Lillie Chair in Childhood Disability Research, McMaster University, Canada

${ }^{4}$ Associate Clinical Professor in the School of Rehabilitation Science, McMaster University, Canada

${ }^{5}$ Managing Associate with REACH Therapy Services, Canada

${ }^{6}$ Assistant Professor in the School of Rehabilitation Science, McMaster University, Canada

${ }^{7}$ Project Coordinator at CanChild, McMaster University, Canada

${ }^{8}$ Assistant Clinical Professor in the School of Rehabilitation Sciences, McMaster University, Canada

Citation: Missiuna, C., Pollock, N., Campbell, W., DeCola, C., Hecimovich, C., Sahagian Whalen, S., ...Camden, C. (2016). Using an innovative model of service delivery to identify children who are struggling in school. British Journal of Occupational Therapy. Advance online publication. doi: $10.1177 / 0308022616679852$

Available at http://journals.sagepub.com/doi/full/10.1177/0308022616679852 
${ }^{9}$ Chief Executive Officer of Central West Community Care Access Centre, Canada.

${ }^{10}$ Peer Mentor at CanChild, McMaster University, Canada

${ }^{11}$ Coordinator for Behavioural Supports Ontario, Hamilton Health Sciences, Canada

${ }^{12}$ Research Assistant at CanChild, McMaster University, Canada

${ }^{13}$ Speech/Language Pathologist and Clinical Researcher at the Children’s Hospital of Eastern Ontario, Canada

${ }^{14}$ Associate Clinical Professor in the School of Rehabilitation Sciences, University of Ottawa, Canada

${ }^{15}$ Research Associate at CanChild, McMaster University, Canada

${ }^{16}$ Professor and Associate Dean in the Faculty of Education, Brock University, Canada

${ }^{17}$ Research Development Officer at CanChild, McMaster University, Canada

${ }^{18}$ Associate Professor in the School of Rehabilitation Science, McMaster University, Canada

${ }^{19}$ Project Manager at CanChild, McMaster University, Canada

${ }^{20}$ Professor in the Faculty of Kinesiology and Physical Education, University of Toronto, Canada

${ }^{21}$ Assistant Professor in the School of Rehabilitation, Sherbrooke University, Canada

${ }^{22}$ Researcher at the Centre Hospitalier Universitaire de Sherbrooke, Canada

\section{Corresponding author:}

Dr. Cheryl Missiuna, McMaster University, School of Rehabilitation Science, 1400 Main St. West, IAHS 412, Hamilton, ON, Canada, L8S 1C7. Email: missiuna@mcmaster.ca 


\begin{abstract}
Introduction

School-age children with motor coordination challenges typically require formal referral for occupational therapy services and often experience lengthy wait times for one-to-one intervention. In a new service delivery model called Partnering for Change, therapists work collaboratively with educators in classrooms to observe, identify, and support children. This study describes children identified through a traditional referral process and compares them with children identified by occupational therapists through classroom observation and dynamic performance analysis.
\end{abstract}

\title{
Methods
}

Participants included 246 children enrolled in a 2-year evaluative study of the Partnering for Change service delivery. Parents completed a demographic questionnaire, the Developmental Coordination Disorder Questionnaire, and the Strengths and Difficulties Questionnaire. Children’s educators completed the Strengths and Difficulties Questionnaire and the School Function Assessment. Children completed the Movement Assessment Battery for Children.

Citation: Missiuna, C., Pollock, N., Campbell, W., DeCola, C., Hecimovich, C., Sahagian Whalen, S., ...Camden, C. (2016). Using an innovative model of service delivery to identify children who are struggling in school. British Journal of Occupational Therapy. Advance online publication. doi: 10.1177/0308022616679852 


\section{Results}

Children identified were significantly younger and more likely to be girls than those referred under the traditional model. Using observation and dynamic performance analysis, occupational therapists identified children who had equally marked difficulties as those who came from the waitlist. In the Partnering for Change model, waitlists for service were eliminated for all children.

\section{Conclusions}

Occupational therapists can identify children who are experiencing significant challenges participating at school without the need for standardized assessment, formal referrals, and waitlists.

\section{Keywords}

Children with disabilities, identification, Partnering for Change 


\section{Introduction}

Service delivery models for school-based occupational therapy services are shifting in many jurisdictions from a referral-based model, where individual students are identified as needing service and referred for occupational therapy, to a population-based model where the therapist supports the whole school in providing inclusive education for all students (American Occupational Therapy Association, 2011; College of Occupational Therapists, 2015; Missiuna et al., 2015). Population-based services typically use a tiered model and Response to Intervention (Bazyk et al., 2012; Hutton et al., 2016). In this model, all students are supported through universal design for learning (UDL), some students who require more assistance are supported through targeted services, often in small groups, and those who continue to struggle receive more individualized or specialized services. The student's response to the intervention that is trialled at each level determines the intensity of service he/she will receive (Cahill et al., 2014).

Over the years, and in many countries, the referral-based model has been shown to have shortcomings including long waitlists, inequities in access, poor coordination of services and limited ability to build educator capacity (Deloitte \& Touche LLP, 2010; Dunford and Richards, 2003; ISD Scotland, 2012). In contrast, therapists working within a population-based model are more integrated into the school team and they can: provide 
services in context; support educators through knowledge translation and collaborative practice; and provide timely service (Campbell at al., 2012; Missiuna et al., 2015).

Some students enter school having been diagnosed with a health condition in their pre-school years (e.g., cerebral palsy, Autism Spectrum Disorder); their needs typically are identified and planned for as they transition to school (Rous et al., 2007). Many other children’s issues are not identified or do not fully emerge, however, until they are schoolaged. This latter group represents a much larger proportion of the student population as they often have high prevalence disorders such as attention deficit hyperactivity disorder (ADHD), learning disabilities and/or developmental coordination disorder (DCD) (American Psychiatric Association, 2013). As occupational therapy services shift toward tiered models of service delivery, it is important to ensure that these students are identified and served as soon as their needs become apparent.

A program of research called Partnering for Change (P4C) afforded the opportunity to study children from 40 schools who had previously been referred and placed on a waitlist through the more traditional model and those who were newly identified by therapists working in those schools using a population-based model. The P4C model of occupational therapy service was developed, implemented, and evaluated in response to the systemic problems identified in existing services within a region in Ontario, Canada. A partnership 
was formed between parents, researchers, therapists, educators, health care decision-makers and the government to develop and evaluate an innovative model that would transform service provision (Missiuna et al., 2012a). The acronym "P4C" was used to reflect the principles of this evidence-based model in which the Partnership between the family, occupational therapist, and educator builds Capacity through Collaboration and Coaching in Context (4Cs) (Missiuna et al., 2012b). The model has changed visually since 2012: the new model is shown in Figure 1.

\section{PARTNERING FOR CHANGE: P4C} Building Capacity through Collaboration and Coaching in Context

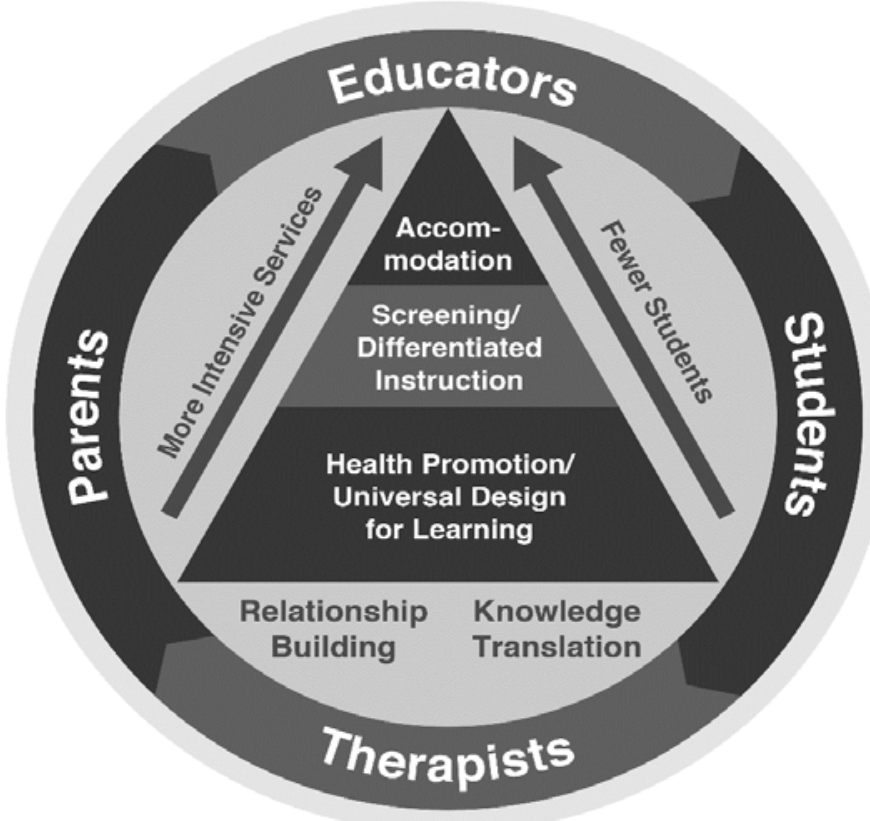

(C) Missiuna, Pollock, Campbell, Levac and Whalen, CanChild, McMaster University, 201€

Citation: Missiuna, C., Pollock, N., Campbell, W., DeCola, C., Hecimovich, C., Sahagian Whalen, S., ...Camden, C. (2016). Using an innovative model of service delivery to identify children who are struggling in school. British Journal of Occupational Therapy. Advance online publication. doi: 10.1177/0308022616679852 
In P4C, students receive intervention of varying intensity depending upon their needs. The whole school is viewed as the client and the occupational therapist's role is to work proactively with educators to collaboratively design physical, social, and learning environments that facilitate successful participation of all students. As can be seen in Figure 1, working from a foundation that focuses on relationship-building and sharing of knowledge with educators, therapists use a tiered model that begins with implementation of concepts from UDL to foster skill development in children of all abilities (Missiuna et al., 2015). Although the model began with an emphasis on fostering fine motor and gross motor skill development, it rapidly expanded to include development of skills needed for performance of many school occupations (e.g., organization, social interactions, selfregulation). They also target services for small groups of children who are experiencing challenges with school occupations, even after the UDL adaptations, and they collaborate with educators to discover and implement methods for differentiating instruction (Missiuna et al., 2012a).

The P4C model enables therapists to observe whole classrooms of school-age children and, in collaboration with educators, to identify children in need of support who may not have been previously identified (Missiuna et al., 2012a). Importantly, occupational therapists do not use formal screening tools or standardized assessments to 
determine which children are struggling and/or require more individualized accommodations; instead, they observe children performing a variety of occupations in settings throughout the school (classroom, hallway, gymnasium, playground). Dynamic performance analysis (DPA) (Polatajko et al., 2000; Polatajko and Mandich, 2004) is an iterative process used by the occupational therapist while observing students performing school-based occupations in their natural context; when a child is having difficulty, the therapist hypothesizes about where and why performance is breaking down. Using DPA in conjunction with knowledge of children's developmental and health conditions and explanatory theories, occupational therapists trial strategies and accommodations until a child is able to participate more fully.

A 2-year study was conducted in which this P4C model was delivered in 40 schools in two health care regions. In the first year, all children who were on waitlists for occupational therapy in these 40 schools were transferred from the local health care agency to the occupational therapists delivering P4C. These children came from the existing referralbased program in which school personnel had identified the children and requested occupational therapy services; if children met the eligibility criteria of the health care 
agency $^{1}$ to receive service, they were put on a waitlist. Children 6 years of age and over can be referred with any occupational performance issue that is impacting on their participation at school, irrespective of diagnosis. Many children are referred with "fine motor", “handwriting”, “sensory” or "gross motor concerns”. In this paper, we will denote the children who came through the referral-based system and were transferred to the P4C therapists to obtain service as "Waitlist” children.

Because the P4C service involved therapists in these 40 schools working closely in classroom contexts with educators, they were able to observe many children who had not previously been identified or referred by the school but who were having difficulty participating in classroom activities. For example, children who, by age 6, were still having significant difficulty learning: to print or to use scissors; to focus on, organize and complete a task; to manage their lunch containers, clothing or knapsacks; to follow daily fitness routines or learn new skills in physical education; to interact socially with their peers on the playground. As well, there were often accompanying behaviours suggesting that the child was frustrated. As per the model, the therapist would first try to see whether changes to the physical, social or learning environment would be sufficient to support the child. If not, then strategies might be collaboratively developed with the educator to differentiate the type of

\footnotetext{
${ }^{1}$ It is important to note that criteria in these regions stated that children had to be 6 years of age unless there was an existing health care condition resulting in health/safety issues.
}

Citation: Missiuna, C., Pollock, N., Campbell, W., DeCola, C., Hecimovich, C., Sahagian Whalen, S., ...Camden, C. (2016). Using an innovative model of service delivery to identify children who are struggling in school. British Journal of Occupational Therapy. Advance online publication. doi: 10.1177/0308022616679852 
instruction or modify the task. Movement through these tiers depended upon the child's response to the intervention; health care consent was sought for children whose needs were greater and who required more individualized strategies. In this study, only the children who were "identified" by the P4C occupational therapists as requiring individualized accommodations were invited to be research participants. All children who were "OTidentified", as well as the "Waitlist” children, received individualized services in a timely manner.

We posed the question: Were occupational therapists, working collaboratively with educators in the P4C service delivery model, able to identify students who were struggling using only observation and dynamic performance analysis? This paper aims to describe and compare the OT-identified children with the children who had been formally referred and were passed along from a waitlist. The working hypothesis was that children who had not previously been identified in the same schools would be less severe in presentation and would have fewer comorbid conditions than those who had been referred through the education system to the health system for occupational therapy services. 


\section{Method}

\section{Design}

Ethics approval was obtained from Hamilton Integrated Research Ethics Board, which is a joint board of Hamilton Health Sciences and McMaster University's Faculty of Health Sciences. The study also was approved by each school board and by the agencies who fund school-based occupational therapy services.

\section{Procedure}

Occupational therapists delivered the P4C service one day per week in 40 schools in three different school boards. In Year 1 of the study, occupational therapists began two months into the school year and started with building relationships with educators and school staff. They began to observe classrooms and to collaboratively identify, with educators, children who were not participating fully. At the same time, children who were in those schools on active service or who were on a waitlist with the local health care agency were also transferred to each P4C occupational therapist for service. Parental consent was requested by the agency and then by the P4C occupational therapist. Once parents gave health care consent, they were invited to participate in the study. As can be seen in Table 1, by the end of the school year, 592 children were receiving occupational therapy services - 241 (40.7\%) had been transferred from the active/waitlist and 351 
(59.3\%) were identified by P4C occupational therapists. 392 families agreed to receive information about the study and 246 families consented to participate. The 246 research participants differed slightly from the 592 children in that parents of younger children who were identified through observation by occupational therapists agreed to receive the P4C health care service but were less likely to agree to participate in the study $(\mathrm{p}<.05)$. The 246 participants did not otherwise differ from the 592 children on the basis of sex or the proportion who came from each health care agency, school or school board.

Upon recruitment into the study, parent questionnaire packages were sent to families that contained a Demographic Questionnaire, the Developmental Coordination Disorder Questionnaire (DCDQ) (Wilson and Crawford, 2009), and the Strengths and Difficulties Questionnaire (SDQ) (Goodman et al., 1998). Depending upon preference, parents were mailed hard copies, or emailed an online version using Research Electronic Data Capture (REDCap; Harris et al., 2009). Data reported are from 246 parent questionnaire packages that were completed in Year 1.

The educator of each child participant also received a hard copy questionnaire package to complete that contained the School Function Assessment (SFA) (Parts 1 and 2) (Coster et al., 1998) and the SDQ. Educator data came from 195 complete educator packages.

Citation: Missiuna, C., Pollock, N., Campbell, W., DeCola, C., Hecimovich, C., Sahagian Whalen, S., ...Camden, C. (2016). Using an innovative model of service delivery to identify children who are struggling in school. British Journal of Occupational Therapy. Advance online publication. doi: 10.1177/0308022616679852 
Based on data collected by the health care region during the referral process, many of the children in the Waitlist group were presumed to have significant motor challenges and, probably, to have DCD. DCD is a chronic health condition and coordination difficulties and difficulty learning new motor tasks are present throughout the child's life. The P4C model discourages the use of standardized assessment of children when they begin to receive service; instead of focusing on children's impairments, $\mathrm{P} 4 \mathrm{C}$ therapists are occupation-centred and focus on discovering solutions, regardless of diagnosis, to improve children's occupational performance. We wanted to know, however, whether occupational therapists were also identifying children with motor challenges and how many children in both groups would meet criteria for probable DCD. Given the assumption that DCD does not "go away", independent assessors administered the Movement Assessment Battery for Children (MABC-2; Henderson et al., 2007), a gold standard assessment for DCD, at the end of Year 2 to all children still participating in the study. The measure was administered to determine whether the children who were referred to the P4C service or identified by the occupational therapists did indeed have motor coordination difficulties. Thirty research participants had moved to non-P4C schools, leaving 216 families. The ethics board only permitted us to approach parents who had provided written consent at the outset of the study (in 5 cases, consent forms were not returned with the questionnaires) resulting in 211 
families. Permission was granted by 156 (74\%) families and MABC-2 assessments were completed with 152 (97\%) of those children.

\section{Measures}

\section{Demographic Questionnaire}

To describe the children and families who participated in this study, parents were asked to provide demographic information regarding the family (for example, income, family composition, parental education, language spoken at home, and employment) as well as medical and developmental information about the child.

Developmental Coordination Disorder Questionnaire (DCDQ; Wilson and Crawford, 2009)

The DCDQ is a 15-item parent-completed measure designed to screen for the types of coordination difficulties in children that could be observed at home. The DCDQ uses a 5-point scale ranging from "Not at all like my child" to "Extremely like my child”. Parents are instructed to rate their child's motor skills in comparison to a child of the same age. The DCDQ is used internationally and has documented reliability and validity (Cairney et 
al., 2008; Loh et al., 2009; Wilson et al., 2009). The wording of the DCDQ was modified slightly with permission from the author. DCDQs with at least 13 or 14 of the 15 items completed were included: missing items (26 cases) were imputed by calculating the average response for that child.

Strengths and Difficulties Questionnaire (SDQ; Goodman et al., 1998)

Parents and educators completed the SDQ, which is a 25-item measure used to screen for behaviour problems in children aged 4-17 years. Each behaviour is rated as being observed “Never”, “Often” or “Always”. The measure is composed of 5 sub-scales including: emotional problems, conduct problems, hyperactivity, peer problems, and prosocial behaviours. The SDQ has adequate reliability and has shown convergent validity with the Child Behaviour Check List and Rutter questionnaire (Goodman, 1997; Goodman and Scott, 1999).

School Function Assessment (SFA; Coster et al., 1998)

The SFA Participation scale provided a measure of the extent to which children are able to participate in the full scope of school activities in a regular classroom, in comparison with their peers. The six-point scale ranges from "Participation extremely limited" to "Full participation"; the expectation is that typically-developing children will have a score of 6 out of 6 , indicating that their level of independence is as expected for their 
age. The SFA was completed by educators who reviewed the participation scale rating instructions on the form and completed the scoring independently.

Movement Assessment Battery for Children $-2^{\text {nd }}$ Edition (MABC-2; Henderson et al., 2007)

The MABC-2 is a standardized test used to identify motor impairment in children aged 3-16 years. In this study, the MABC-2 was administered individually in each child's school by trained research assistants. Eight motor tasks were scored in 3 categories: Manual Dexterity; Aiming \& Catching; and Balance (static and dynamic). Studies have shown that the MABC-2 is a reliable and valid tool for the assessment of movement difficulties, even in young children, and can be helpful in identifying children with probable DCD (those who score below the $16^{\text {th }}$ percentile) (Henderson et al., 2007).

\section{Data Analysis}

Study data were collected and managed using REDCap electronic data capture tools hosted at McMaster University (Harris et al., 2009). All statistical analyses were completed using IBM SPSS Statistics Version 22.0 (IBM Corporation 2013).

Citation: Missiuna, C., Pollock, N., Campbell, W., DeCola, C., Hecimovich, C., Sahagian Whalen, S., ...Camden, C. (2016). Using an innovative model of service delivery to identify children who are struggling in school. British Journal of Occupational Therapy. Advance online publication. doi: 10.1177/0308022616679852 


\section{Results}

\section{Demographics}

The 246 children who participated ranged in age from 4 to 13 years and had a mean age

of 8.19 (1.67 SD) years. Children identified by occupational therapists were approximately one year younger than children who were from the Waitlist group $(\mathrm{t}(244)=3.95, \mathrm{p}<0.001)$. Within the group of children who were OT-identified and were research participants, 11.4\% of children were in kindergarten (aged 4-5 years). Although families agreed to the P4C service but not to participate in the study, it is noteworthy that 72 children who were only 4-5 years old were identified by occupational therapists as requiring individualized accommodations; the mean age of the OT-identified group in the study would have been even lower, if those children had been included. In the referral-based model, only 3 children were referred who were below 6 . As is evident in Table 1, 115 research participants were from the health care agency Waitlist, 97 (84.3\%) males and 18 (15.7\%) females, while 131 participants were OT-identified, 91 males (69.5\%) and 40 (30.5\%) females. Occupational therapists identified proportionately more girls, in comparison with the sex ratio of the Waitlist group $\left(\mathrm{X}^{2}=7.53, \mathrm{p}<.001\right)$. 
As shown in Table 1, in addition to identifying motor coordination challenges or coordination difficulties, parents most commonly reported that their child had a cooccurring diagnosis of speech/language difficulties, with ADHD and learning disabilities also frequently noted ${ }^{2}$. There was no significant difference in numbers of children with other conditions who came from the Waitlist or were OT-identified $\left(\mathrm{X}^{2}=4.22 ; \mathrm{p}>.05\right.$. $)$ Many children (56\%) from both groups had from one to three other health or developmental conditions in addition to motor coordination challenges, suggesting that there were many underlying reasons for their school struggles.

Very few children (14.2\%) were reported to have a formal designation of exceptionality within the education system. According to parent report, at the beginning of the study, 37.8\% of children had an Individualized Education Plan (IEP) that captured their need for accommodations in the classroom. Significantly more of these children came from the Waitlist group $\left(\mathrm{X}^{2}=10.89, \mathrm{p}<0.001\right)$ indicating that their need for differentiated instruction

${ }^{2}$ During participant recruitment in Year 1, P4C therapists did not provide services to selfcontained classrooms. For this reason, children with Autism Spectrum Disorder, Cerebral Palsy, Down Syndrome (and other health conditions in which children may have coordination difficulties) were not recruited, if they were placed in a self-contained classroom. Further, the majority of children who have a disability that can be recognized prior to school entrance receive therapy services from children's treatment centres, not the local health care agency.

Citation: Missiuna, C., Pollock, N., Campbell, W., DeCola, C., Hecimovich, C., Sahagian Whalen, S., ...Camden, C. (2016). Using an innovative model of service delivery to identify children who are struggling in school. British Journal of Occupational Therapy. Advance online publication. doi: 10.1177/0308022616679852

Available at http://journals.sagepub.com/doi/full/10.1177/0308022616679852 
or accommodations had already been recognized by the school system; suggestions had not

yet been made by an occupational therapist as they were still waiting to be seen.

Table 1. Description of Children in the Study.

\begin{tabular}{|c|c|c|c|c|}
\hline $\begin{array}{l}\text { Children who Received } \\
\text { Partnering for Change Services }\end{array}$ & $\begin{array}{l}\text { Waitlist } \\
\mathrm{n}=241(40.7 \%)\end{array}$ & $\begin{array}{l}\text { OT-identified } \\
\mathrm{n}=351(59.3 \%)\end{array}$ & $\begin{array}{l}\text { Total } \\
n=592\end{array}$ & Test Statistic \\
\hline \multicolumn{5}{|l|}{ Sex } \\
\hline $\begin{array}{l}\text { Male } \\
\text { Female }\end{array}$ & $\begin{array}{l}201(83.4 \%) \\
40(16.6 \%)\end{array}$ & $\begin{array}{l}264(75.2 \%) \\
87(24.8 \%)\end{array}$ & $\begin{array}{l}465(78.5 \%) \\
127(21.5 \%)\end{array}$ & $X^{2}=5.69^{*}$ \\
\hline \multicolumn{5}{|l|}{ Age } \\
\hline $\begin{array}{l}\text { Mean Age } \\
\text { (Range) }\end{array}$ & $\begin{array}{l}8.81 \\
(5-12 \text { years })\end{array}$ & $\begin{array}{l}7.52 \\
\text { (3-14 years) }\end{array}$ & $\begin{array}{l}8.04 \\
\text { (3-14 years) }\end{array}$ & $\mathrm{t}(590)=9.35^{* * *}$ \\
\hline \multicolumn{5}{|l|}{ Grade } \\
\hline $\begin{array}{l}\text { Kindergarten } \\
\text { Grades 1-3 } \\
\text { Grades 4-8 } \\
\end{array}$ & $\begin{array}{l}3(1.2 \%) \\
130(53.9 \%) \\
108(44.8 \%) \\
\end{array}$ & $\begin{array}{l}72(20.5 \%) \\
218(62.1 \%) \\
61(17.4 \%) \\
\end{array}$ & $\begin{array}{l}75(12.7 \%) \\
348(58.8 \%) \\
169(28.5 \%) \\
\end{array}$ & $\mathrm{X}^{2}=81.17^{* * *}$ \\
\hline $\begin{array}{l}\text { Children who Consented to } \\
\text { Participate in the Study }\end{array}$ & $\begin{array}{l}\text { Waitlist } \\
\mathrm{n}=115 \text { (47.7\%) }\end{array}$ & $\begin{array}{l}\text { OT-Identified } \\
\mathrm{n}=131(37.3 \%)\end{array}$ & $\begin{array}{l}\text { Total } \\
\mathrm{n}=246\end{array}$ & $X^{2}=6.36^{*}$ \\
\hline \multicolumn{5}{|l|}{ Sex } \\
\hline $\begin{array}{l}\text { Male } \\
\text { Female }\end{array}$ & $\begin{array}{l}97(84.3 \%) \\
18(15.7 \%)\end{array}$ & $\begin{array}{l}91(69.5 \%) \\
40(30.5 \%)\end{array}$ & $\begin{array}{l}188(76.4 \%) \\
58(23.6 \%)\end{array}$ & $X^{2}=7.53^{* *}$ \\
\hline \multicolumn{5}{|l|}{ Age } \\
\hline $\begin{array}{l}\text { Mean Ageb } \\
\text { (Range) }\end{array}$ & $\begin{array}{l}8.62 \\
(5-12 \text { years })\end{array}$ & $\begin{array}{l}7.81 \\
\text { (4-13 years) }\end{array}$ & $\begin{array}{l}8.19 \\
\text { (4-13 years) }\end{array}$ & $\mathrm{t}(244)=3.95^{* * *}$ \\
\hline \multicolumn{5}{|l|}{ Grade } \\
\hline $\begin{array}{l}\text { Junior and Senior } \\
\text { Kindergarten } \\
\text { Grades } 1-3\end{array}$ & $\begin{array}{l}1(0.9 \%) \\
68(59.1 \%)\end{array}$ & $\begin{array}{l}15(11.4 \%) \\
82(62.6 \%)\end{array}$ & $\begin{array}{l}16(6.5 \%) \\
150(61.0 \%)\end{array}$ & $\mathrm{X}^{2}=14.38^{* * *}$ \\
\hline
\end{tabular}

Citation: Missiuna, C., Pollock, N., Campbell, W., DeCola, C., Hecimovich, C., Sahagian Whalen, S., ...Camden, C. (2016). Using an innovative model of service delivery to identify children who are struggling in school. British Journal of Occupational Therapy. Advance online publication. doi: $10.1177 / 0308022616679852$

Available at http://journals.sagepub.com/doi/full/10.1177/0308022616679852 
Grades 4-8

Co-Occurring Diagnoses

Attention deficit

hyperactivity disorder

Speech/language

Learning Disabilities

Autism Spectrum

Disorder

Other

Other Characteristics

Born pre-term

Individualized Education

Plan

\section{Family Demographics}

Families who speak

English at home

Families living below

poverty line

Parent completed at least

some college/university

Partner completed at least

some college/university

$$
46(40.0 \%) \quad 34(26.0 \%) \quad 80(32.5 \%)
$$

$\begin{array}{llll}21(18.3 \%) & 27(20.6 \%) & 48(19.5 \%) & \\ 33(28.7 \%) & 26(19.8 \%) & 59(24.0 \%) & \\ 24(20.9 \%) & 23(17.6 \%) & 47(19.1 \%) & X^{2}=4.22 \\ 4(3.5 \%) & 3(2.3 \%) & 7(2.8 \%) & \\ 47(40.9 \%) & 67(51.1 \%) & 118(48.0 \%) & \end{array}$

$20(17.4 \%) \quad 27(20.6 \%)$

$47(19.1 \%) \quad X^{2}=0.41$

$56(48.7 \%)$

$37(28.2 \%)$

$93(37.8 \%)$

$\mathrm{X}^{2}=10.89^{* * *}$

a Age calculated from date of healthcare consent

b Age calculated from date of study recruitment

* $\quad \mathrm{p}<.05$

$* * \quad \mathrm{p}<.01$

$* * * \quad \mathrm{p}<.001$

With regard to family demographics, 214 (87\%) of respondents were mothers; 28 (11.4\%) were fathers. The majority of families had two or three children and two parents

Citation: Missiuna, C., Pollock, N., Campbell, W., DeCola, C., Hecimovich, C., Sahagian Whalen, S., ...Camden, C. (2016). Using an innovative model of service delivery to identify children who are struggling in school. British Journal of Occupational Therapy. Advance online publication. doi: 10.1177/0308022616679852 
(81.7\%). In most families, both parents worked outside of the home for pay (72\%); 61 (24.8\%) had one spouse who was caring for the family full-time. Most families spoke English in the home (79.7\%). The median income was $\$ 60,000$ to $\$ 80,000$ (CAD); however, $19.5 \%$ of families had incomes below the provincial poverty line. Most (80.9\%) parent respondents had completed college or a university degree; spouses/partners were less likely to have completed post-secondary education. There was no significant difference in any demographic when families whose children were in the Waitlist group were compared with families of children who were OT-identified.

\section{DCDQ}

As can be seen in Table 2, 239 (97\%) parents completed the DCDQ. Using the DCDQ cut-off scores for probable DCD showed that 132 (55\%) of parents indicated that their children were demonstrating significant motor challenges that impacted on daily activities outside of school. OT-identified children who had these motor challenges were younger and more apt to be female than were children in the Waitlist group. Of interest, in the OT-identified group, girls in the two younger age bands were rated by parents as demonstrating more motor difficulties (lower score) than boys in the same age group. 
Table 2. Developmental Coordination Disorder Questionnaire (DCDQ) Results.

\begin{tabular}{lllll}
\hline Characteristic & $\begin{array}{l}\text { Waitlist } \\
\mathrm{n}=112(46.9 \%)\end{array}$ & $\begin{array}{l}\text { OT-identified } \\
\mathrm{n}=127(53.1 \%)\end{array}$ & $\begin{array}{l}\text { Total } \\
\mathrm{n}=239\end{array}$ & Test Statistic \\
\hline $\begin{array}{l}\text { DCDQ scores below cutoff } \\
\text { Sex }\end{array}$ & $60(53.6 \%)$ & $72(56.7 \%)$ & $132(55.2 \%)$ & $\mathrm{X}^{2}=0.19$ \\
$\quad$ Male & $50(44.6 \%)$ & $47(37.0 \%)$ & $97(40.6 \%)$ & $\mathrm{X}^{2}=5.48^{*}$ \\
$\quad$ Female & $10(8.9 \%)$ & $25(19.7 \%)$ & $35(14.6 \%)$ & \\
\hline $\begin{array}{l}\text { Mean DCDQ Score by Age } \\
\text { Band and Sex }\end{array}$ & $\mathrm{n}$ (Mean Score, SD) & $\mathrm{n}$ (Mean Score, SD) & $\mathrm{n}$ (Mean Score, SD) & Test Statistic \\
\hline 5-7 years and 11 months & 11 & 30 & 41 & \\
$\quad$ Male & $9(37.33,4.21)$ & $18(37.44,6.03)$ & $27(37.41,5.41)$ & \\
$\quad$ Female & $2(41.00,5.66)$ & $12(35.00,6.32)$ & $14(35.86,6.41)$ & \\
8-9 years and 11 months & 35 & 29 & 64 & \\
$\quad$ Male & $29(42.66,8.33)$ & $20(46.25,6.78)$ & $49(44.12,7.86)$ & $\mathrm{X}^{2}=8.38^{\mathrm{b} *}$ \\
$\quad$ Female & $6(45.67,6.05)$ & $9(42.11,9.60)$ & $15(43.53,8.30)$ & \\
$\geq 10$ years & 14 & 13 & 27 & \\
$\quad$ Male & $12(48.75,5.77)$ & $9(40.78,9.48)$ & $21(45.33,8.40)$ & \\
Female & $2(41.00,4.24)$ & $4(46.25,10.63)$ & $6(44.50,8.87)$ &
\end{tabular}

a According to cut-off scores on DCDQ for probable DCD at each age band

$\mathrm{b} \quad$ Based on number of children in each group by age band

* $\quad \mathrm{p}<.05$

\section{Strengths and Difficulties Questionnaire}

A comparison of scores on the SDQ indicated that the Waitlist group did not differ from the OT-identified group on total number of difficulties according to the parents $(\mathrm{M}=12.43 ; \mathrm{SD}=6.01$ and $\mathrm{M}=13.24 ; \mathrm{SD}=6.48$ respectively; $\mathrm{t}(242)=1.02, \mathrm{p}>.05)$ or the children's educators ( $\mathrm{M}=12.02 ; \mathrm{SD}=6.76$ and $\mathrm{M}=11.82$; $\mathrm{SD}=6.37$; $\mathrm{t}(192)=0.21, \mathrm{p}>.05)$.

Citation: Missiuna, C., Pollock, N., Campbell, W., DeCola, C., Hecimovich, C., Sahagian Whalen, S., ...Camden, C. (2016). Using an innovative model of service delivery to identify children who are struggling in school. British Journal of Occupational Therapy. Advance online publication. doi: 10.1177/0308022616679852 Available at http://journals.sagepub.com/doi/full/10.1177/0308022616679852 
Similarly, the percentage of children whose total difficulties scores on the SDQ were in a clinically significant range did not differ between groups (22.6\% and 32.8\% for the Waitlist and OT-identified group according to parent report; 32\% and 27.8\% for the groups according to educator report). It is important to note that, overall, a large proportion of children in this study were reported by both parents (28.3\%) and educators (29.9\%) to have difficult behaviours that were scored as "abnormal". The most elevated sub-scale in both groups was Hyperactivity $(\mathrm{M}=5.33$; $\mathrm{SD}=2.73$ and $\mathrm{M}=5.67 ; \mathrm{SD}=2.80$ for Waitlist and $\mathrm{OT}$ identified according to parent report and $\mathrm{M}=5.95 ; \mathrm{SD}=2.90$ and $\mathrm{M}=5.97 ; \mathrm{SD}=2.91$ according to educator report, respectively).

\section{School Function Assessment}

The participation scores reported by educators did not differ across the two groups ( $\mathrm{M}=4.38 ; \mathrm{SD}=1.37$ and $\mathrm{M}=4.43 ; \mathrm{SD}=1.40$ for Waitlist and OT-Identified groups, respectively) $(\mathrm{t}(177)=2.41, \mathrm{p}>.05)$. Given that typically developing children are usually rated as 6/6, the low mean scores of participants in both groups indicated that children who received individualized attention from $\mathrm{P} 4 \mathrm{C}$ therapists were struggling with many activities and demonstrated modified participation at school; that is, most were requiring some assistance from adults to participate in all aspects of school life. 


\section{Movement Assessment Battery of Children}

The purpose of administering the MABC-2 at the end of the study was to determine whether the children who were receiving individualized services actually had significant motor challenges. We had assumed that many of the children on the waitlist were referred for that reason but had no evidence to substantiate this claim. Table 3 shows that $70 \%$ of the children seen in both groups were considered to have probable DCD as they scored below the $16^{\text {th }}$ percentile on this measure; indeed, $86 \%$ of the children who scored below the $16^{\text {th }}$ percentile also scored below the $5^{\text {th }}$ percentile in one or more motor domains, indicating significant motor challenges.

Table 3. Movement Assessment Battery for Children - 2 (MABC-2) Results.

\begin{tabular}{llll}
\hline $\begin{array}{l}\text { Movement Assessment Battery for } \\
\text { Children - 2 Results }\end{array}$ & $\begin{array}{l}\text { Waitlist } \\
\mathrm{n}=73(48.0 \%)\end{array}$ & $\begin{array}{l}\text { OT-identified } \\
\mathrm{n}=79(52.0 \%)\end{array}$ & $\begin{array}{l}\text { Total } \\
\mathrm{n}=152\end{array}$ \\
\hline Sex & & & \\
$\quad$ Male & 62 & 52 & 114 \\
$\quad$ Female & 11 & 27 & 38 \\
Mean Standard Score & 6.23 & 5.97 & 6.10 \\
Mean Percentile & 19.41 & 16.95 & 18.13 \\
Percentile Category & & & \\
$\quad \leq 1 \%$ & 16 & 18 & 34 \\
2-5\% & 18 & 18 & 36 \\
6-16\% & 15 & 21 & 36 \\
Children considered pDCD $(\leq 16 \%)^{\mathrm{a}}$ & $49(67 \%)$ & $57(72 \%)$ & $106(70 \%)$ \\
$\quad$ Male & 40 & 41 & 81 \\
Female & 9 & 16 & 25 \\
Children considered pDCD and $\leq 5 \%$ & $42(86 \%)$ & $50(88 \%)$ & $92(86 \%)$
\end{tabular}

Citation: Missiuna, C., Pollock, N., Campbell, W., DeCola, C., Hecimovich, C., Sahagian Whalen, S., ...Camden, C. (2016). Using an innovative model of service delivery to identify children who are struggling in school. British Journal of Occupational Therapy. Advance online publication. doi: 10.1177/0308022616679852 Available at http://journals.sagepub.com/doi/full/10.1177/0308022616679852 
in any domain of $M A B C-2$

$\begin{array}{llll}\text { Male } & 33 & 36 & 69 \\ \text { Female } & 9 & 14 & 23\end{array}$

a pDCD: probable developmental coordination disorder

\section{Discussion and Implications}

This paper examined whether children who received occupational therapy services after being formally identified and placed on a waitlist differed in any substantive way from children who were identified in classrooms through occupational therapist observation and DPA. We hypothesized that children who had not previously been identified might be less severe in presentation or would have fewer comorbid health conditions or behavioural problems. This hypothesis was rejected.

Through collaboration with educators, P4C occupational therapists were able to identify children who were not able to participate fully in classroom occupations (Polatajko et al., 2000). With only two notable exceptions, age and sex, the characteristics of children in the OT-identified group, compared to the Waitlist group, were nearly identical on all measures. This indicates that therapists' use of observation and DPA was effective in identifying children with motor coordination challenges, and other types of attentional, 
learning and social challenges to performing school occupations, without the use of standardized assessments.

OT-identified children were on average one year younger than those on the waitlist. As was pointed out earlier, however, the traditional service does not usually permit referral of children into the system until they are 6 years of age so one could argue that the comparison is unfair. What is important to note, however, is that educators, together with therapists, were able to identify these children at 4 and 5 years of age through observation and that the children were determined to be finding it hard to manage daily occupations. In fact, more than $20 \%$ of the 351 children who the occupational therapists identified in the first year of the study were under 6 years of age. The current policy in the traditional service is keeping children from receiving support when their needs are first identified. Despite changes to the environment and suggestions regarding differentiated instruction, it is clear that many of these young children required more individualized strategies in order to participate successfully. This type of early identification is critical for prevention of secondary disability (Missiuna et al., 2014). Artificial barriers to requesting occupational therapy support (such as age, grade or requiring a diagnosis) are present in many systems and mean that young children often must struggle for two years before receiving the 
support that they need. Further, once referred, the 18-24 month waitlist presents yet another delay.

The other major finding in this study was that the OT-identified group contained proportionately more girls than the Waitlist group. When observing whole classrooms of children, P4C occupational therapists were able to notice many girls who were struggling but who had not been referred. Various explanations have been suggested to explain the higher proportion of boys who are referred by the education system, including an increased likelihood that boys externalize their frustrations (Rivard et al., 2007). Interestingly, girls in the two younger age bands of the OT-identified group were also given lower scores on the DCDQ by parents (indicating greater motor difficulty) than boys in the same age group. This finding differs from a population-based study where girls were consistently rated higher on the DCDQ than boys of the same age (Rivard et al., 2014). Our findings suggest that the girls being identified by P4C therapists are actually experiencing many more motor challenges out of school than their peers and that their parents were able to share this information by completing the DCDQ.

As seen by the results of the MABC-2 and the DCDQ, 70\% of the OT-identified and Waitlist children presented with significant motor coordination challenges, across age groups. It is interesting to note that $30 \%$ of children did not exhibit motor difficulties on the 
MABC-2, which suggests that factors such as attentional or other psychosocial difficulties may have been contributing to their occupational issues in school. This interpretation of our data is consistent with the many additional health conditions that parents in both groups reported on the Demographic Questionnaire and also with the finding that hyperactivity/attentional difficulties were most frequently reported on the SDQ by both parents and educators.

If the occupational therapist had not been present in these classrooms, working collaboratively with educators, the OT-identified children may never have been recognized and referred and certainly would not have received occupational therapy service in a timely way. The population-based model created equitable opportunities for children to immediately access the support they needed to participate, and in so doing, promoted occupational justice for children who were unable to participate fully in schools (Durocher et al., 2014).

\section{Limitations}

The point was made that therapists were able to identify children who were not participating fully at a younger age with a population-based model; however, young children were not able to be referred in the traditional model and were inevitably older at the time of referral so conclusions about age differences between the groups cannot be 
made with certainty. Further, some schools were so frustrated at the lengthy waitlists that they were referring very few children. Therefore, while we know that occupational therapists were able to identify these young children, we cannot conclude that the traditional model would be unable to identify and refer these children, if permitted to do so. Time would still be lost in the traditional service, however, during completion of multiple forms by teachers, principals and parents, followed by a long waitlist. The Participation section of the SFA was completed by the educator reviewing the instructions on the scoring sheet itself, not by reviewing the rating scale guide. This study might have benefited from inclusion of measures that captured the child's perspective on their ability to participate fully. Further studies are required to validate conclusions about waitlists and program effectiveness.

\section{Conclusion}

Various approaches have been trialed in an effort to decrease the long waiting lists for occupational therapy support for children who are experiencing motor challenges in school (Dunford at al., 2004; Green et al., 2005). In this study, lengthy existing waitlists were completely eliminated in 40 schools as P4C therapists provided school-based services to those children; in addition, many other children in those schools received support who 
might not otherwise have been identified or determined to be eligible for service. These children presented with nearly identical severity of motor challenges, presence of cooccurring conditions, and difficult behaviours as those who had been referred and were waiting for service. Although many similarities were evident, children from waitlists differed from those identified by occupational therapists and educators on sex and age. Through P4C, children in both the Waitlist group and the OT-identified group received service and their needs were recognized. The P4C model contributed to an occupationally just system, where each child had equitable access to the support needed to participate in valued occupations at school.

\section{Key Findings:}

1. Occupational therapists can identify struggling children through observation, dynamic performance analysis and collaboration with educators.

2. Partnering for Change facilitates earlier identification of, and timely intervention for, children struggling in school.

\section{What the study has added:}

There is strong movement in UK, Canada, and US toward using tiered models of service

delivery but this is the first study to systematically develop, refine, implement and evaluate such a model. 


\section{Research ethics}

Ethics approval was obtained from Hamilton Integrated Research Ethics Board, which is a joint board of Hamilton Health Sciences and McMaster University’s Faculty of Health Sciences (Project number: 13-022; ethics approved: January 28, 2013; ethics renewal approved: January 8, 2014 and January 7, 2015). The study also was approved by each school board and by the agencies who fund school-based occupational therapy services.

\section{Declaration of conflicting interest}

The Authors declare that there is no conflict of interest.

\section{Acknowledgements}

The authors would like to thank the children, families, health care decision-makers, educators and school communities, occupational therapists, and team members who contributed to this study.

\section{Funding}

The authors are grateful to the Ontario Ministries of Health and Long-Term Care and Education for funding this research, to the Central West and Hamilton Niagara Haldimand Brant Community Care Access Centres who provided funding for occupational therapy services through School Health Support Services, and to the partners and stakeholders who 
provided leadership, funding of the health services and contributed to the research activities.

Citation: Missiuna, C., Pollock, N., Campbell, W., DeCola, C., Hecimovich, C., Sahagian Whalen, S., ...Camden, C. (2016). Using an innovative model of service delivery to identify children who are struggling in school. British Journal of Occupational Therapy. Advance online publication. doi: 10.1177/0308022616679852

Available at http://journals.sagepub.com/doi/full/10.1177/0308022616679852 


\section{References}

American Occupational Therapy Association (2011) Occupational therapy services in early childhood and school-based settings. American Journal of Occupational Therapy 65 (Suppl.): S46-S54.

American Psychiatric Association (2013) Diagnostic and statistical manual of mental disorders: DSM-5. Arlington, VA: American Psychiatric Publishing, Inc.

Bazyk S, Berthelette M, Cahill S, et al. (2012) AOTA practice advisory on occupational therapy in Response to Intervention. Available at: https://www.aota.org//media/corporate/files/practice/children/browse/school/RtI/AOTA\%20RtI\%20practice \%20Adv\%20final\%20\%20101612.pdf (accessed 10 March 2016).

Cahill SM, McGuire B, Krumdick ND, et al. (2014) National survey of occupational therapy practitioners’ involvement in Response to Intervention. American Journal of Occupational Therapy 68: e234-e240. 
Cairney J, Missiuna C, Veldhuizen S, et al. (2008) Evaluation of the psychometric properties of the Developmental Coordination Disorder Questionnaire for Parents (DCD-Q): Results from a community based study of school-aged children. Human Movement Science 27(6): 932-940.

Campbell W, Missiuna C, Rivard L, et al. (2012) “Support for Everyone”: Experiences of occupational therapists delivering a new model of school-based services. Canadian Journal of Occupational Therapy 79(1): 51-59.

College of Occupational Therapists (2015) Occupational therapy evidence: Fact sheet. Occupational therapy with children and young people. Available at: https://www.cot.co.uk/sites/default/files/commissioning_ot/public/OT-with-childrenand-young-people-updated-April2015.pdf (accessed 8 March 2016).

Coster W, Deeney T, Haltiwanger J, et al. (1998) School function assessment. San Antonio, TX: Psychological Corporation. 
Deloitte \& Touche LLP (2010) Review of school health support services: Final report. Report for the Ontario Ministry of Health and Long Term Care, 10 July.

Dunford C and Richards S (2003) Doubly disadvantaged: A report of a survey on waiting lists and waiting times for occupational therapy services for children with developmental coordination disorder. London: College of Occupational Therapists, National Association of Paediatric Occupational Therapists.

Dunford C, Street E, O’Connell H, et al. (2004) Are referrals to occupational therapy for developmental coordination disorder appropriate? Archives of Disease in Childhood 89(2): 143-147.

Durocher E, Gibson B and Rappolt S (2014) Occupational justice: A conceptual review. Journal of Occupational Science 21(4): 418-430.

Goodman R (1997) The Strengths and Difficulties Questionnaire: A research note. Journal of Child Psychology and Psychiatry 38(5): 581-586. 
Goodman R and Scott S (1999) Comparing the Strengths and Difficulties Questionnaire and the Child Behavior Checklist: Is small beautiful? Journal of Abnormal Child Psychology 27(1): 17-24.

Goodman R, Meltzer H and Bailey V (1998) The Strengths and Difficulties Questionnaire: A pilot study on the validity of the self-report version. European Child \& Adolescent Psychiatry 7(3): 125-130.

Green D, Bishop T, Wilson B, et al. (2005) Is questionnaire-based screening part of the solution to waiting lists for children with developmental coordination disorder? British Journal of Occupational Therapy 68(1): 2-10.

Harris P, Taylor R, Thielke R, et al. (2009) Research electronic data capture (REDCap) - A metadata-driven methodology and workflow process for providing translational research informatics support. Journal of Biomedical Informatics 42(2): 377-81.

Henderson S, Sugden D and Barnett A (2007) The Movement Assessment Battery for Children ( $2^{\text {nd }}$ Ed.). London: Pearson Assessment. 
Hutton E, Tuppeny S and Hasselbusch A (2016) Making a case for universal and targeted children's occupational therapy in the United Kingdom. British Journal of Occupational Therapy 79(7): 450-453. Epub ahead of print 1 February 2016. DOI: $10.1177 / 0308022615618218$

IBM Corp (2013) IBM SPSS Statistics for Windows, Version 22.0 [Software]. Armonk, NY: IBM Corp.

ISD Scotland (2012) Findings from the AHP waiting times census in Scotland.

Edinburgh: ISD Scotland Publications. Available at:

http://www.isdscotland.org/Health-Topics/Waiting-Times/Publications/2012-0710/2012-07-10-AHPWaitingTimes-Report.pdf (accessed 8 March 2016).

Loh P, Piek J and Barrett N (2009) The use of the developmental coordination disorder questionnaire in Australian children. Adapted Physical Activity Quarterly 26(1): 38-53. 
Missiuna C, Cairney J, Pollock N, et al. (2014) Psychological distress in children with developmental coordination disorder and attention-deficit hyperactivity disorder. Research in Developmental Disabilities 35(5): 1198-1207.

Missiuna C, Pollock N, Campbell W, et al. (2012a) Use of the Medical Research Council Framework to develop a complex intervention in pediatric occupational therapy: Assessing feasibility. Research in Developmental Disabilities 33(5): 14431452.

Missiuna C, Pollock N, Campbell W, et al. (2015) Partnering for change: Embedding universal design into school-based occupational therapy. Occupation Therapy Now 17(3): 13-15.

Missiuna C, Pollock N, Levac D, et al. (2012b) Partnering for Change: An innovative school-based occupational therapy service delivery model for children with developmental coordination disorder. Canadian Journal of Occupational Therapy 79(1): 41-50. 
Polatajko HJ and Mandich A (2004) Key feature 2: Dynamic performance analysis (DPA). In: Polatajko HJ and Mandich A (eds) Enabling occupation in children: The cognitive orientation to daily occupational performance (CO-OP) approach. Ottawa, Ontario: Canadian Association of Occupational Therapists Publications ACE, pp. 6066.

Polatajko HJ, Mandich A and Martini R (2000) Dynamic performance analysis: A framework for understanding occupational performance. American Journal of Occupational Therapy 54(1): 65-72.

Rivard L, Missiuna C, Hanna S, et al. (2007) Understanding teachers’ perceptions of the motor difficulties of children with DCD. British Journal of Educational Psychology 77(3): 633-648.

Rivard L, Missiuna C, McCauley D, et al. (2014) Descriptive and factor analysis of the Developmental Coordination Disorder Questionnaire (DCDQ'07) in a population-based sample of children with and without Developmental Coordination Disorder. Child: Care, Health and Development 40(1): 42-49. 
Rous B, Myers CT and Stricklin SB (2007) Strategies for supporting transitions of young children with special needs and their families. Journal of Early Intervention 30(1): 1-18.

Wilson BN and Crawford SG (2009) The Developmental Coordination Disorder Questionnaire. Retrieved from http://dcdq.ca.libaccess.lib.mcmaster.ca/ (accessed 9 October 2012).

Wilson BN, Crawford SG, Green D, et al. (2009) Psychometric properties of the revised Developmental Coordination Disorder Questionnaire. Physical \& Occupational Therapy in Pediatrics 29(2): 182-202.

Citation: Missiuna, C., Pollock, N., Campbell, W., DeCola, C., Hecimovich, C., Sahagian Whalen, S., ...Camden, C. (2016). Using an innovative model of service delivery to identify children who are struggling in school. British Journal of Occupational Therapy. Advance online publication. doi: $10.1177 / 0308022616679852$ 